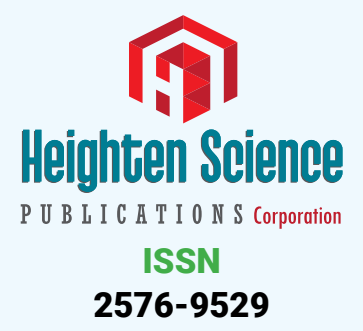

*Address for Correspondence: Helene Georgery, Université catholique de Louvain, CHU UCL Namur, Department of Internal Medicine and Nephrology, site Sainte-Elisabeth, 15 Place Louise Godin, Namur, Belgium, Tel: +32494143793; Email: helene.georgery@hotmail.com

Submitted: 03 December 2018 Approved: 13 December 2018 Published: 14 December 2018

Copyright: (c) 2018 Georgery H, et al. This is an open access article distributed under the Creative Commons Attribution License, which permits unrestricted use, distribution, and reproduction in any medium, provided the original work is properly cited.

Keywords: ADPKD; Kidney transplant; Liver cyst infection; Treatment; CA19-9; PET/CT

Check for updates
Case Report

\section{Liver cyst infection in kidney transplant patient with autosomal dominant polycystic kidney disease: Interest of PET/CT in diagnosis and treatment}

\author{
Georgery H*, Migali G, Pochet JM, Tintillier M, Van Ende $\mathrm{C}$ and \\ Cuvelier C \\ Université catholique de Louvain, CHU UCL Namur, Department of Internal Medicine and \\ Nephrology, site Sainte-Elisabeth, 15 Place Louise Godin, Namur, Belgium
}

\section{Abstract}

Liver cyst infection in patients with autosomal dominant polycystic kidney disease (ADPKD) is a rare but life-threatening complication. Diagnosis and treatment remain challenging. We report the case of a 64-year-old kidney transplant patient presenting with fever and abdominal pain. The diagnosis of liver cyst infection was made by positron emission tomography scan (PET/CT). Moreover, the course of our patient illustrates the interest of subsequent PET/CT during follow-up as our patient failed on antibiotherapy and required liver cyst drainage.

\section{Introduction}

Autosomal dominant polycystic kidney disease (ADPKD) is the most common genetic cause of chronic kidney disease affecting about one in 1000 live births and representing 5 to $10 \%$ of the patients undergoing renal replacement therapy.

Liver cyst is the most common extrarenal lesion in ADPKD. Liver cysts generally remain asymptomatic with a preserved liver function but occasionally can lead to abdominal discomfort, chronic pain, cyst rupture, intracystic bleeding or infection.

Liver cyst infection is a rare $5 \%$ of ADPKD patients together with liver cyst bleeding [1]) but severe complication potentially leading to sepsis and death. It is far less frequent than renal cyst infection but more severe and involving multiple and larger cysts [2]. Recurrences are also common, affecting $20 \%$ of patients in Lantiga's metaanalysis [3].

Ultrasonography, computed tomography scan (CT) and magnetic resonance imaging (MRI) have poor performance to detect infected cysts [4]. In contrast, PET/ CT is now considered as the best imaging technique to identify liver cyst infection in ADPKD patients. PET/CT may be also helpful in the follow-up to evaluate the response to antibiotherapy [5], as illustrated by our patient who finally required cyst drainage.

\section{Case Report}

A 64-year-old male patient with ADPKD was admitted for weakness, loss of appetite, abdominal pain, cough and lower limb oedema for 3 weeks. Past history included a cadaveric renal transplantation in 1998, chronic cholestasis from polycystic hepatic disease, chronic lymph oedema secondary to everolimus and several infections diagnosis and treatment. J Clini Nephrol. 2018; 2: 053-056. https://doi.org/10.29328/journal.jcn.1001019 
(Haemophilus influenzae meningitis, Morganella morganii and Klebsiella pneumoniae pyelonephritis and two sepsis with $E$. Coli attributed to probable liver cyst infections). Current medications were ciclosporine, methylprednisolone $4 \mathrm{mg}$, spironolactone/ altizide, bisoprolol, atorvastatine and febuxostat. On physical examination, the patient was apyretic. Saturation was $94 \%$ with $1,5 \mathrm{~L}$ oxygen. We noted right lung hypoventilation, hepatomegaly, right flank tenderness, lower limb and flanks oedema. The biology disclosed an inflammatory syndrome (C-reactive protein or CRP 140 $\mathrm{mg} / \mathrm{L}$ ) with neutrophilic leucocytosis (9400 neutrophils $/ \mathrm{mm}^{3}$ ), a rapidly resolutive rise in creatinine $(2.29 \mathrm{mg} / \mathrm{dL}$, usually $0.9 \mathrm{mg} / \mathrm{dL})$ and a chronic known cholestasis. The chest radiography suggested a right lower lobe pneumonia. An antibiotherapy with moxifloxacine was initiated and shifted five days later to piperacilline/tazobactam because of persistent inflammatory syndrome. An abdominal CT showed ascites and suspected a possible peritoneal carcinomatosis. The PET/CT revealed metabolic activity of the left bowel and a suspicion of liver cyst infection. The colonoscopy did not disclose any tumour Carbohydrate antigen 19-9 (CA19-9) was dosed at 349.6 U/mL.

After a favourable evolution for 3 weeks under piperacilline/tazobactam, fever recurred and the inflammatory syndrome increased. Meropenem was initiated. One week later, as the fever persisted as the inflammatory syndrome, an exploratory coelioscopy was performed, ruling out the carcinomatosis but showing a neutrophilic peritonitis with Douglas pouch abscess. Culture of peritoneal fluid was sterile but blood cultures revealed Morganella morganii sensitive to piperacilline/tazobactam and meropenem. However, two weeks later, 3 weeks after the initiation of meropenem, the patient presented fever again and CRP was $70.2 \mathrm{mg} / \mathrm{dL}$. A new PET/CT showed increased metabolic activity of the liver cyst wall. Liver cyst was punctured and a percutaneous drainage was performed. Cultures of liver cyst fluid were negative.

The evolution was then favourable and the drain was withdrawn 18 days later. After 6 weeks of meropenem since cyst drainage, CRP decreased to $16.6 \mathrm{mg} / \mathrm{L}$, CA19-9 from 349.6 to $102.4 \mathrm{U} / \mathrm{mL}$ and a third PET/CT showed complete disappearance of the metabolic activity of the liver cyst (Figure 1).

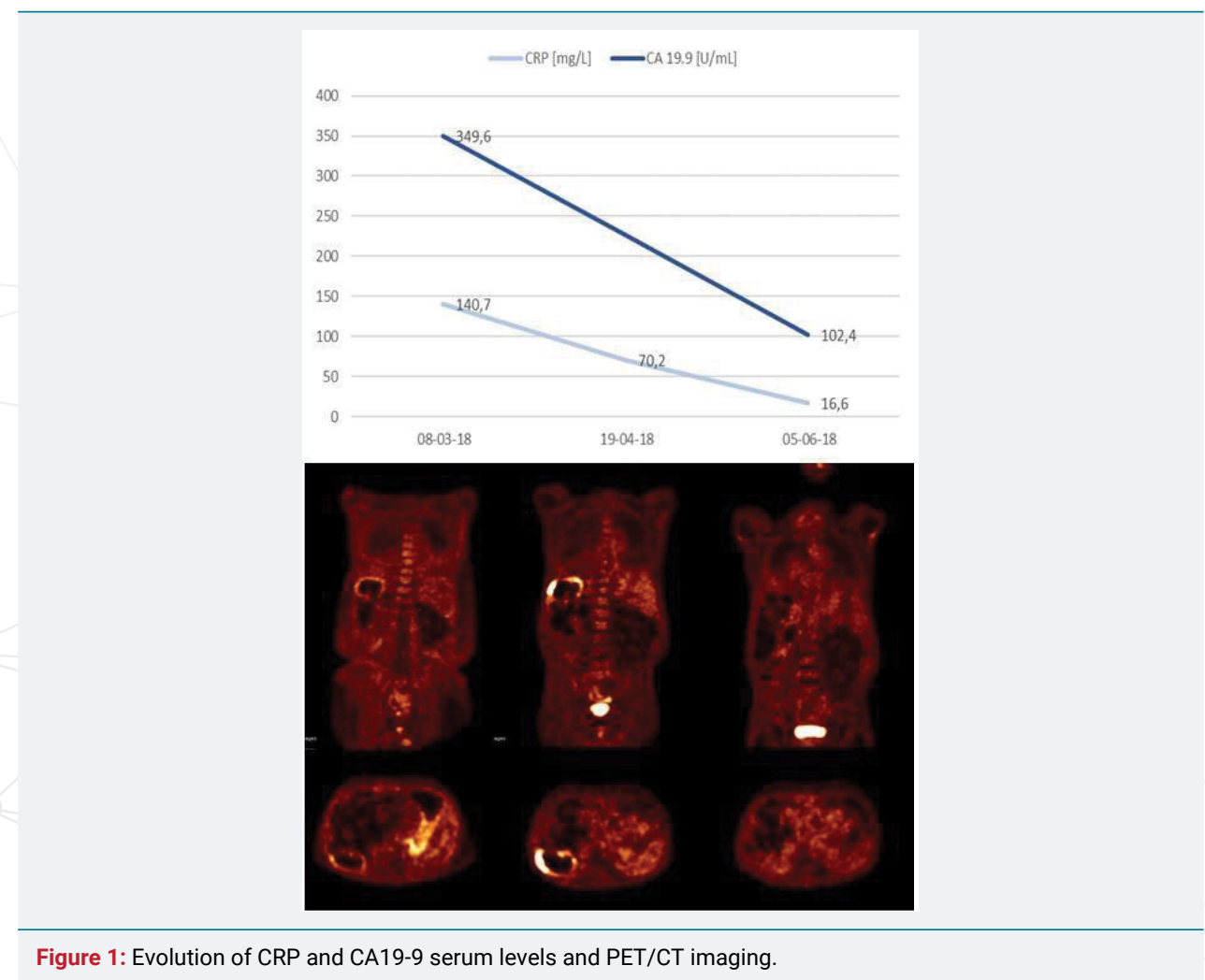




\section{Discussion}

Patients with liver cyst infection usually present with fever, right upper quadrant pain and leukocytosis. Diagnosis is ideally confirmed with cyst fluid bacteriology. However, drainage is rarely performed and alternative diagnostic methods include clinical, biochemical and imaging findings. Lantiga et al. recently summarized diagnostic criteria for liver cyst infection: infection is « definite » if confirmed by cyst content analysis showing bacteria or neutrophils, infection is «probable » if the four following criteria are concomitantly met: 3 -day fever $>38^{\circ} \mathrm{C}$, liver tenderness, CRP plasma levels $>50 \mathrm{mg} / \mathrm{L}$ and no CT evidence for cystic haemorrhage. Additional criteria are weight loss, recent instrumentation of biliary tract and increased white blood cell count [6].

CA19-9 level is higher in ADPKD patients than in the general population, depending on gamma-glutamyl transferase serum level and liver volume [7]. It is also higher in case of inflammation and liver cyst infection. Because of variable basal level and the lack of established cut-off values, a measurement of baseline CA19-9 level may be of value in ADPKD patients to help for diagnosis and monitoring of liver cyst infection [7].

Nowadays, PET/CT is the best diagnostic tool for liver cyst infection in ADPKD patients with a sensitivity of $100 \%$ for definite and $93 \%$ for probable cyst infections in the Lantiga's series [8]. The specificity of PET/CT remains to be determined, especially for differential diagnosis with intracystic bleeding.

The treatment of liver cyst infection includes antibiotics and may require percutaneous drainage when antibiotics alone failed or for cysts larger than $5 \mathrm{~cm}$ [4]. Obviously drainage requires that the infected cyst can be distinguished from noninfected cysts and is accessible to puncture. The Kidney Disease Improving Global Outcomes (KDIGO) recommends lipid-permeable anti-microbial agents for treatment of liver cyst infection, such as fluoroquinolones and trimethoprimsulfamethoxazole, depending on sensitivity (if available) [9]. Sallee et al. note the superiority of bitherapy to monotherapy in liver cyst infection in ADPKD patients [4]. E. Coli, Klebsiella spp. and Enterococcus spp. were the most frequent isolated causative microorganisms in liver cyst infections in Suwabe's series [10]. Although previous liver cyst infections $(>=4)$ and hepatomegaly $\left(>3000 \mathrm{~cm}^{3}\right)$ are associated with a decreased sensitivity of E. coli for fluoroquinolones [10], it remains the standard treatment and may be superior to beta-lactamines [4]. Studies of cyst penetration of newer antibiotics are needed. As for renal cyst infection, duration of antibiotherapy is not well defined. Because of high risk or recurrence, a minimum of 6 weeks is recommended [11]. The KDIGO defines the eradication of infection by the disappearance of fever, normalization of CRP levels, and at least two negative blood and/or urine cultures. Antibiotics alone fail in $70 \%$ of patients despite multiple switches [2] and percutaneous drainage or surgery is often necessary, as illustrated by our patient.

In conclusion, we have described the case of a 64-year-old kidney transplant patient with ADPKD presenting a liver cyst infection. Diagnosis was confirmed by PET/ CT imaging. Antimicrobials with piperacilline/tazobactam, then meropenem alone were insufficient and liver cyst drainage was required. The decision of drainage was supported by the PET/CT showing its interest in the follow-up and treatment of liver cyst infection.

\section{References}

1. Gall TM, Oniscu GC, Madhavan K, Parks RW, Garden OJ. Surgical management and longterm followup of non-parasitic hepatic cysts. HBP (Oxford). 2009; 11: 235-241. Ref.: https://goo.gl/nXsEUK

2. Pirson $\mathrm{Y}$, Kanaan $\mathrm{N}$. Complications infectieuses associées à la polykystose rénale autosomique dominante. Nephrol ther. 2015; 11: 73-77. Ref.: https://goo.gl/7XVxEt

3. Lantinga MA, Geudens A, Gevers TJG, Drenth JPH. Systematic review: the management of hepatic cyst infection. Aliment Pharmacol Ther. 2015; 41: 253-261. Ref.: https://goo.gl/B33yyd 
4. Sallee M, Rafat C, Zahar JR, Paulmier B, Grunfeld JP, et al. Cyst infections in patients with Autosomal Dominant Polycystic Kidney Disease. Clin J Am Soc Nephrol. 2009; 4: 1183-1189. Ref.: https://goo.gl/UKhJVJ

5. Lantinga MA, De Sevaux RG, Drenth JP. 18F-FDG PET/CT during diagnosis and followup of recurrent hepatic cyst infection in autosomal dominant polycystic kidney disease. Clin Nephrol. 2015; 84: 61-64. Ref.: https://goo.gl/4JUrij

6. Neuville M, Hustinx R, Jacques J, Krzesinski JM, Jouret F. Diagnostic Algorithm in the Management of Acute Febrile Abdomen in Patients with Autosomal Dominant Polycystic Kidney Disease. PLoS ONE. 2016; 11: e0161277. Ref.: https://goo.gl/zbGgUP

7. Fukasawa $\mathrm{H}$, Kaneko $M$, Niwa $H$, Yasuda $H$, Kumagai $H$, et al. Carbohydrate antigen 19-9 is significantly elevated in autosomal dominant polycystic kidney disease. Nephrology (Carlton). 2018; 23: 210-216. Ref.: https://goo.gl/awzFJ6

8. Lantiga MA, Drenth JP, Gevers TJ. Diagnostic criteria in renal and hepatic cyst infection. Nephrology Dialysis Transplantation. 2015; 30: 744-7451. Ref.: https://goo.gl/p5Qjj4

9. Chapman AB, Devuyst O, Eckardt KU, Gansevoort RT, Harris T, et al. Autosomal Dominant Polycystic Kidney Disease (ADPKD): Executive Summary from a Kidney Disease: Improving Global Outcomes (KDIGO) Controversies Conference. Kidney international. 2015; 88: 17-27. Ref.: https://goo.gl/RtcfYY

10. Suwabe T, Araoka H, Ubara $Y$, Kikuchi $K$, Hazue R, et al. Cyst infection in autosomal dominant polycystic kidney disease: causative microorganisms and susceptibility to lipidsoluble antibiotics. Eur J Clin Microbiol Infect Dis. 2015; 34: 1369-1379. Ref.: https://goo.gl/yd4XSB

11. Pirson $Y$, Chauveau D, Devuyst O. Autosomal dominant polycystic kidney disease. In: Davidson AM, editor. Oxford textbook of clinical nephrology. 3rd ed, Oxford: Oxford University Press. 2005; 2304-24 